Biomechanics in Paralympics: Implications for performance

\begin{tabular}{|r|l|}
\hline Journal: & International Journal of Sports Physiology and Performance \\
\hline Manuscript ID & IJSPP.2016-0199.R2 \\
\hline Manuscript Type: & Invited Brief Review \\
\hline Keywords: & $\begin{array}{l}\text { biomechanics, exercise performance, physical performance, sport, special } \\
\text { needs populations }\end{array}$ \\
\hline \multicolumn{2}{|c}{} \\
\hline
\end{tabular}

SCHOLARONE ${ }^{m}$

Manuscripts 


\section{Biomechanics in Paralympics: Implications for performance}

2

3 Briefreview

4

5 Floor Morriën ${ }^{\mathrm{a}, \mathrm{b}}$, Matthew J.D. Taylor ${ }^{\mathrm{a}}$, Florentina J. Hettinga ${ }^{\mathrm{a}}$

6 a School of Biological Sciences, Centre for Sports and Exercise Science, University of Essex, 7 Colchester, Wivenhoe Park, Colchester CO4 3SQ United Kingdom

$8{ }^{\mathrm{b}}$ Center for Human Movement Sciences, University Medical Center Groningen, University of 9 Groningen, Groningen, A. Deusinglaan 1, 9713 AV Groningen, The Netherlands

10

11

12

13

14

15

16

17

18

19

20

21

\section{Corresponding author:}

Florentina J. Hettinga, Ph.D.

School of Biological Sciences, Centre for Sports and Exercise Science, University of Essex, Colchester, Wivenhoe Park, Colchester CO4 3SQ United Kingdom

Phone: +441206872046

E-mail: fjhett@essex.ac.uk

Preferred Running Head:

Biomechanics in Paralympics

Abstract Word Count: 228

Text-Only Word Count: 4306

Number Tables: 4

Number of Figures: 1 
Purpose: To provide an overview of biomechanical studies in Paralympic research and their relevance for performance in Paralympic sports. Methods: Search terms 'Paralympic Biomechanics', 'Paralympic Sport Performance', 'Paralympic Athlete Performance', and 'Paralympic Athlete' were entered into the electronic database PubMed. Results: Thirty-four studies were included. Biomechanical studies in Paralympics mainly contributed to performance enhancement by technical optimization $(n=32)$ and/or injury prevention $(\mathrm{n}=6)$. Also, biomechanics was found to be important in understanding activity limitation caused by various impairments, relevant for evidence-based classification in Paralympic sports $(\mathrm{n}=6)$. Distinctions were made between biomechanical studies in sitting $(41 \%)$, standing (38\%), and swimming athletes $(21 \%)$. In sitting athletes, kinematics and kinetics in wheelchair propulsion were mostly studied, mainly in spinal cord injured athletes. Also kinetics and/or kinematics in wheelchair basketball, seated discus throwing, stationary shot putting, handcycling, sit-skiing and ice sledge hockey received attention. In standing sports, kinematics of amputee athletes performing jump sports and running, and the optimization of prosthetic devices were primarily investigated. No studies were reported on other standing sports. In swimming, kick rate and resistance training were mainly studied. Conclusions: Biomechanical research is important for performance by gaining insight into technical optimization, injury prevention and evidence-based classification in Paralympic sports. Future studies are advised to also include physiological as well as biomechanical measures, allowing the assessment of the capability of the human body as well as the resulting movement.

Keywords: Physical disability, adapted sports, sports performance, performance enhancement, athletes.

\section{Introduction}

At the 2012 Paralympics, one of the world's largest sporting events, over 160 countries and more than 4000 athletes with different disabilities competed in over 500 medal events (www.paralympic.org). Twenty-eight sports were included: Twenty-three summer sports (Archery, Athletics, Boccia, Canoe, Cycling, Equestrian, Football 5-a-side, Football 7-a-side, Goalball, Judo, Powerlifting, Rowing, Sailing, Shooting, Sitting volleyball, Swimming, Table tennis, Triathlon, Wheelchair basketball, Wheelchair dance, Wheelchair fencing, Wheelchair rugby and Wheelchair tennis) and five winter sports (Alpine skiing/ snowboarding, Biathlon, Cross-country skiing, Ice sledge hockey, Wheelchair curling).

Biomechanical analyses have proven to be extremely important in enhancing sports performance. For Paralympic athletes, biomechanical analysis is even more important, since it will help understand how different impairments limit activity and sports performance. To obtain a better understanding of Paralympic sports and the performance determining factors, it is important to give an overview of biomechanical research and its relevance for performance conducted in Paralympic sports. Relatively recently Keogh published a review on biomechanics in Paralympic summer sports. ${ }^{1}$ The present review updates and expands upon the review conducted by Keogh, however is unique in giving an overview of biomechanical research and its relevance for performance in Paralympic sports and Paralympic athletes as it covers all sports and disability groups which have been published in the literature, including 
Paralympic Winter sports. Following this overview, we hope to obtain more insights into the relevance and practical applications of biomechanics in Paralympic sports and athletes. Specifically, we hope to distillate relevant practical advices for coaches and athletes, ultimately directed at improving Paralympic sports performance.

\section{Methods}

With the intention to obtain all papers reporting on biomechanics in Paralympic sports and Paralympic athletes, the key words "Paralympic Biomechanics", "Paralympic Sport Performance", "Paralympic Athlete Performance" and "Paralympic Athlete" were entered into PubMed (July 2016). All studies on biomechanics in Paralympic and World Class athletes were included, including case-studies. Interviews, editorials, reviews, studies not available online and studies not in English were excluded (Figure 1).

\section{Insert figure 1 about here}

\section{Results}

Twenty articles were identified using the keywords "Paralympic Biomechanics", 124 using the keywords "Paralympic Sport Performance", 110 using the keywords "Paralympic Athlete Performance", and 220 using the keywords "Paralympic Athlete". After applying the exclusion criteria, eleven, ${ }^{2-12}$ ten, ${ }^{13-22}$ one, ${ }^{23}$ and seven ${ }^{24-30}$ articles were selected respectively. Based on the authors' knowledge, five more studies were included, ${ }^{31-35}$ on biomechanics in Paralympic athletes. In total, 34 studies were included (Tables 1-3). One case-study ${ }^{36}$ was selected using the keywords "Paralympic Biomechanics" and two ${ }^{37-38}$ using the keywords "Paralympic Sport Performance" (Table 4). Based on the authors' knowledge, four more casestudies were included (Table 4). ${ }^{39-42}$

Biomechanical studies in Paralympic athletes (non case-studies) mainly contributed to performance enhancement by technical optimization $(n=32)^{2-10,12-28,30-35}$ and injury prevention $(n=6)$ (Tables 1-3). ${ }^{3,14,22,24,25,29}$ Also, biomechanics were important in evidence-based classification in Paralympic sports $(n=6$; some studies addressed more than one of these points) (Tables 1-3). ${ }^{5,6,10,11,17,32}$ In the current review, sports were subdivided into three main groups based on Bernardi et al. ${ }^{43}$ : sitting, standing, and visually-impaired athletes. However, no studies specifically on visually impaired athletes and biomechanics were found. Instead, several studies on biomechanics and swimming were included, and we defined swimming as a third group, replacing the group of visually-impaired athletes.

Studies on biomechanics in Paralympic summer ( $\mathrm{n}=29,85 \%$ of the included studies) and winter sports $(n=5,15 \%$ of the included studies), the number of participants, type of sport, type of impairment, test used, and main outcome are presented (Tables 1-3). Thirteen studies (38\% of the included studies) $)^{5-11,17,23,27,30-32}$ were performed during the Paralympic Games or World Championships, whereas the remaining twenty-one studies $(62 \%$ of the included studies) were performed in a laboratory setting studying Paralympic athletes. ${ }^{2-4,12-}$ 16,18-22,24-26,28,29,33-35 Furthermore, $41 \%(\mathrm{n}=14)$ of the studies were performed on sitting sports, $38 \%$ on standing sports $(n=13)$, and $21 \%(n=7)$ on swimming. Sports were analyzed from a kinematic and/or kinetic point of view. In sitting athletes ( $n=14,41 \%$ of the included studies), summer sports $(n=9$, Table 1$)$ were represented more than winter sports $(n=5$, Table 1$)$.

\section{Sitting sports}


117 Regarding summer sports, kinetics and kinematics of wheelchair propulsion were widely 118 studied $(\mathrm{n}=4)$ in terms of push-rim forces, ${ }^{24}$ wrist biomechanics, ${ }^{3}$ and shoulder and elbow motion. ${ }^{25}$ Forces, moments, and kinematics were described during tests in which subjects propelled a standard daily wheelchair, equipped with a SMART ${ }^{\text {Wheel }} 5$, on a computer controlled dynamometer at different speeds. These studies were performed in order to understand and prevent upper limb injuries such as wrist, shoulder and elbow injuries in manual wheelchair users; they all contributed to the creation of a reference database on daily wheelchair propulsion technique in elite athletes, ${ }^{3,24,25}$ which eventually could be used to enhance performance and prevent injuries in sports.

Biomechanical research also generated evidence relevant for optimizing performance and evidence-based classification in several summer sports (wheelchair basketball, handcycling, discus throwing, and stationary shot putting). Wang et al. ${ }^{22}$ investigated the kinematics and kinetics of wheelchair basketball. Coaches are advised to focus on increasing sitting height and range-of-motion of shoulder internal rotation and elbow flexion, elbow extension and range-of-motion of wrist extension, and quick visual reaction time to increase the average rebounds, points and number blocks per game respectively. Range-of-motion and muscle strength of wrist flexion/extension should receive more attention in wheelchair basketball training. Hence applying wrist- shoulder- and arm skills training should enhance wheelchair performance.

Handcycling could successfully be modeled using the power balance model (Table 1), providing insights into the power production and losses during handcycling. The power balance allows predictions of performance in cyclic activities. For hand cycling, power output of the handcyclist, average power loss to air friction, internal friction and rolling friction, and average change of mechanical energy of the system (hand cyclist and handcycle together) are taken into account. In turn, the power balance model can be used for estimating exercise responses of Paralympic athletes when there is no possibility for direct measurements. ${ }^{34}$

In seated discus throwing, whole body position and feet position characteristics provided key information on the relationship between throwing technique and the throwing frame (customized sport equipment attached onto the plate from where the discus is thrown) (Table 1). ${ }^{5,6}$ The base of support of elite discus throwers in F30 classes (athletes having moderate to severe hypertonia, ataxia and/or athetosis in limbs and/or trunk, varying from severe to moderate loss of functional control over the classes F31 to F34 respectively www.paralympic.org) could be described by the feet position as well as the whole body position. ${ }^{6}$ This knowledge contributes toward optimizing the competitive conditions for seated discus throwers, such as the design of the throwing frame for seated discus throwers, the interaction between the throwing technique and the throwing frame, and the throwing technique. Also, this knowledge is relevant for the debate on the design of throwing frames and classification in seated discus throwing. Kinematic analysis has increased the understanding of stationary shot putting (Table 1). ${ }^{17,32}$ To develop an evidence-based classification system for stationary shot putters, performances of 114 Paralympic athletes were analyzed (Table 1). ${ }^{17}$ The methods of analysis (comparative matrices, performance continuum, and dispersion plots) were found to work well in obtaining biomechanical variables and helped to better understand the dispersion of classification-related variables. The results from stationary shot putting and seated discus throwing provide important information to enhance performance, and contribute to further development of evidence-based classification, which will ensure fair and equal competition in these sports. ${ }^{5,6,17,32}$ Coaches and athletes should focus on increased velocity and angle of the shot at release. ${ }^{32}$

For winter sports, only cross-country sit-skiing and ice sledge hockey have been studied. $^{7,21,23,28}$ Kinematics in cross-country sit-skiing showed that speed, and therefore performance, decreased during the race (substantiated by evaluating changes in the kinematic 
parameters cycle speed, cycle duration, push phase speed, recovery phase speed, pole inclination, trunk inclination and shoulder-hand distance) (Table 1). ${ }^{23}$ As this speed decrement was attributed to early fatigue and a relatively low physical fitness, slower cross-country sitskiers were advised to increase their physical fitness by focusing on strength and explosive power training and by improving maximal aerobic power and glycolytic capacity, to optimize their performance. ${ }^{23}$ The biomechanics of the double poling technique in cross-country sitskiers were successfully analyzed using unique field data obtained via markerless kinematic analysis in Paralympics competition. ${ }^{7}$ Coaches and athletes are advised to focus on improving physical fitness ${ }^{23}$ and use the markerless kinematic analysis technique based on video-analysis during competition to visualize and analyze the double-poling techniques to improve performance in cross-country sit-skiing.

The interaction between the athlete and the equipment used in sit-skiing was addressed by designing a new sit-ski to facilitate control of the center of mass (CoM) and inertia of the sit ski/skier system, in the anterior-posterior direction (Table 1). ${ }^{19}$ Control of the CoM in the anterior-posterior direction influences sit-ski dynamics and how the ski mechanically interacts with the snow surface, which was relevant for enhancing performance.

In ice sledge hockey, high correlations were found between upper-body strength, power and sprint performance in highly trained athletes. The ability to produce high frequency propulsion (i.e. a poling push-off in the opposite direction of movement) was found to be important for sprint abilities (Table 1). ${ }^{21}$ In addition, heavy upper-body strength training (6weeks, 3-weekly sessions of 3x6-8RM) improved upper-body strength as well as sprint abilities (Table 1). ${ }^{28}$ Strength gains correlated with improvements in sprint abilities. In particular, a high load during strength training was effective for enhancing sprint abilities (especially acceleration) in sports where upper-body acceleration and maximal speed are important for performance. ${ }^{28}$

\section{Insert Table 1 about here}

\section{Standing sports}

In standing sports $(\mathrm{n}=13)$, research focused mainly on unilateral lower limb amputees $(\mathrm{n}=9$, Table 2) $2,8-10,12,27,30,31,35$ compared to bilateral lower limb amputees $\left(n=3\right.$, Table 2). ${ }^{2,31,35}$ Athletes with a transtibial amputation (TTA, $n=9)^{2,8-10,12,27,30,31,35}$ were most researched compared to athletes with a transfemoral amputation (TFA, $n=3$ ) ${ }^{4,8,13}$ Only one study evaluated biomechanics in standing athletes with cerebral palsy (CP) ${ }^{20}$ and one study with visually-impaired standing athletes. $^{29}$

Regarding summer sports in standing athletes, research increased the understanding of activity limitation and performance determining factors in Paralympic athletes. Several studies $(\mathrm{n}=4$, Table 2$)$ analyzed the kinematics of unilateral amputee long and high jumpers. ${ }^{8-}$ ${ }^{10,27}$ In able-bodied (AB) athletes, a long-jump model has been established, where a positive relation exists between approach speed and distance jumped. Optimal take-off technique included lowering the CoM during the last few steps, obtaining the right body posture at touch-down, and successfully 'pivoting' over the take-off leg to generate sufficient vertical velocity while minimizing losses in horizontal velocity. ${ }^{8}$ Female TTA conformed to the longjump model established for $\mathrm{AB}$ long-jump technique, although some technical adaptations were noticed. ${ }^{8}$ These adaptations caused a less effective use of the horizontal approach speed in these athletes compared to $\mathrm{AB}$ and male amputee athletes. In contrast, TFA did not conform to the long-jump model, possibly because of the excessive lowering of their CoM at touch-down, creating a greater downward vertical velocity which negatively influenced jump 
performance (Table 2). ${ }^{8}$ Coaches and athletes should be cautious about translating techniques used by $\mathrm{AB}$ long-jumpers to athletes jumping with prostheses. In addition, while differences in technique were observed (Table 2) depending on take-off strategy, ${ }^{27}$ take-off using the prosthetic limb versus take-off using the intact limb did not affect jump distance. However, a low number of athletes were included in the study, so conclusions must be interpreted with caution. ${ }^{27}$ Lastly, although a longer residual shank (stump length) may provide a longer and stronger lever arm, Nolan et al. ${ }^{10}$ found that residual shank length was not an important determinant of long-jump performance, suggesting it is appropriate for all TTA long-jumpers to compete in the same class. In the high jump, TTA athletes showed some similarities in jump technique compared to $\mathrm{AB}$ athletes (Table 2). ${ }^{9}$ Even though an understanding of the differences in technique compared to $\mathrm{AB}$ athletes has provided significant information for coaching, and has the potential to contribute to performance enhancement in lower limb amputee long-jump and high-jump athletes, a better understanding of the mechanisms of amputee jumpers is still needed. ${ }^{9}$ As residual shank length had no effect on distance jumped, technique, prosthesis and training play a more important role in long-jump performance ${ }^{10}$ and are advised to be addressed in jump sports training sessions. In addition, these findings are important for evidence-based classification, to establish fair and equal competition in Paralympic jumping athletes.

Amputee running has received considerable attention ${ }^{2,4,13,31,35}$ (Table 2). Lowering the prosthetic knee joint center in unilateral TFA runners improved inter-limb symmetry, and subsequently running velocity, ${ }^{13}$ whereas running on standard running prosthesis resulted in a larger inter-limb asymmetry (Table 2). ${ }^{4}$ These findings suggest that by improving the method of alignment of the prosthesis running performance can be increased. ${ }^{13}$ In addition, three studies $^{2,31,35}$ evaluated unilateral as well as bilateral TTA sprinters (Table 2). Arellano et al. ${ }^{2}$ performed a study on mediolateral foot placement variability and found that maintaining lateral balance became increasingly difficult at faster speeds but was equally challenging for sprinters with and without a unilateral TTA. ${ }^{2}$ For bilateral TTA athletes, it was most challenging to maintain lateral balance. In addition, asymmetries in medio-lateral foot placement were seen in unilateral TTA sprinters, suggesting that the use of running-specific prostheses results in a compensatory foot placement strategy for maintaining lateral balance in sprinters with unilateral TTA. ${ }^{2}$ Furthermore, leg stiffness was important in sprinting (Table 2) (increased vertical stiffness is associated with faster speed and decreased contact time, while decreased leg stiffness in affected legs with running specific prostheses was due to lower peak ground reaction forces and increased leg compression with increasing speeds) and was different between biological legs and affected legs with running specific prostheses. ${ }^{35}$ Also, a low step count $(<50$ steps) was found to be a factor for success in lower-limb amputee sprinters since the converse may indicate the prosthesis requires further adjustments. ${ }^{31}$ Although Habora ${ }^{30}$ showed that amputation side does not influence sprinting performance, a more recent study on maximum speed curve running in TTA athletes showed slower speed in the curves with the affected leg on the inside compared with curves with the affected leg on the outside. ${ }^{12}$ Orientation of the affected leg seemed to limit speed more than curve-running direction. ${ }^{12}$ These insights help to understand the race-based behavior of amputee athletes and provide information for the discussion on the performance of lower-limb prostheses. However, actual 'in competition analysis' similar to that of $\mathrm{AB}$ sprinters ${ }^{45}$ has yet to be undertaken for Paralympic sprinters.

The only study on standing athletes with $\mathrm{CP}$, and the only study involving EMG, claimed that power output during a $30-\mathrm{sec}$ Wingate cycle test was higher in $\mathrm{AB}(\mathrm{AB})$ athletes compared to athletes with $\mathrm{CP}$, whereas both groups were equally fatigued (Table 2). ${ }^{20}$ Bilateral EMG activity of five muscles (erector spinae, gluteus medius, biceps femoris, gastrocnemius, vastus lateralis) was measured in both legs during a 10-sec sprint test, a 30-sec 
Wingate anaerobic sprint test and in a rested state. No differences in mean muscle activity were found between the able-bodied and CP groups. For all measured muscles but the vastus lateralis, EMG amplitude decreased significantly over the trial in both limbs in CP and ablebodied groups. Vastus lateralis activity remained unchanged. Elite athletes with $\mathrm{CP}$ seem to have the ability to adapt towards levels of $\mathrm{AB}$ athletes, which can most likely be attributed to their high-level of training over many years. ${ }^{20}$

In a group of visually-impaired athletes, athlete guides (those who assist visuallyimpaired running athletes) and athletes with upper- and distal lower limb deficiencies, isokinetic muscle strength and self-reported musculoskeletal complaints were investigated. ${ }^{29}$ Increases in knee flexor and extensor muscles in both lower limbs were found over time (assessments took place at three time points over one year working towards a competition) (Table 2). ${ }^{29}$ In addition, muscle imbalance was associated with the occurrence of knee and thigh complaints. The simultaneous investigation of athletes' musculoskeletal complaints and muscle strength may contribute to the identification and treatment of injuries in Paralympic athletes by obtaining better understanding into satisfactory musculoskeletal development. ${ }^{29}$

\section{Insert Table 2 about here}

\section{Swimming}

Seven studies analyzed swimming athletes (Table 3). ${ }^{11,14-16,18,26,33}$ A 6-week dry-land resistance training program improved swimming performance by eliciting increased strength and power, dive starts, and free swimming velocity (Table 3). ${ }^{14}$ Also, strengthening the shoulder girdle increased muscular and joint stability and control, reducing the risk of injuries. The evaluation of biomechanics in relation to training thus seems important, as adequate training improves technique and consequently reduces the risk of the occurrence of injuries. To enhance swimming performance and reduce the risk of injuries, coaches and swimmers are encouraged to undertake continuous dry-land training programs throughout the season. ${ }^{14}$ From an anthropometric point of view, especially male Paralympic swimmers with lowseverity physical disabilities and female Paralympic swimmers with mid-severity physical disabilities, swimmers should be encouraged to develop muscle mass and upper body power to enhance performance (Table 3). ${ }^{16}$ To further optimize swimming performance, coaches can benefit from identifying four specific measures in swimming - time, distance, velocity and force - during the three primary phases of the swim-start: the block, flight, and underwater phases. During swim-starts, the free-swim period is a critical phase for all Paralympic swimmers regardless of the severity of their disability, while the block and underwater phase are specifically critical for upper body, lower body, and palsy disabilities (Table 3). ${ }^{15}$ This is because large correlations were found between free-swim velocity and the International Point Score (IPS, a performance level), and the free-swimming velocity accounted for between $67 \%-75 \%$ of the variation in $50-\mathrm{m}$ performance. Also, a lower velocity during the block and underwater phases was associated with slower times towards $15 \mathrm{~m}$ in all disability groups (i.e. upper body, lower body, palsy). ${ }^{15}$

An increased kick rate contributed to faster swimming speeds (Table 3) ${ }^{18}$ The kick rate and amplitude profile that Paralympic swimmers showed in Fulton et al. ${ }^{33}$ (i.e. a large amplitude kicking and a decreased kick rate) are appropriate for optimizing net force (Table 3), relevant information for developing training programs.

Biomechanics-based classification in swimming was also investigated by relating passive drag force to swimming class. Negative associations between drag force and swimming class were found, where the most severely impaired swimmers experienced highest 
passive drag (Table 3). ${ }^{11}$ However, as the mean difference in drag between classes was found to be inconsistent, it was concluded that the current classification system does not always differentiate clearly between swimming groups. ${ }^{11}$

\section{Insert Table 3 about here}

\section{Case-studies}

Case-studies on wheeling, ${ }^{38}$ cycling, ${ }^{37}$ long-jump, ${ }^{36}$ and sprinting ${ }^{39-42}$ Paralympic athletes are listed (Table 4). These case-studies have helped athletes to choose an optimum hand rim diameter for wheeling. ${ }^{38}$ In addition, they helped to optimize equipment-user interface (Table $4),{ }^{37}$ both important for improving sports performance. The case-study of an upper limb amputee long-jumper showed that the addition of extra arm mass did not improve jump performance (Table 4). ${ }^{36}$ Amputee sprinting has received most attention $(n=4)$. Specifically, there has been much debate in the literature ${ }^{39,40}$ regarding the biomechanics of amputee sprinting compared to $\mathrm{AB}$ sprinting, with a focus on whether amputee sprinters have an advantage when competing against $\mathrm{AB}$ sprinters, thus offering a unique take on classification.

It is established that increased hip work on the prosthetic limb acts as the major compensatory mechanism that allows TTA athletes to run. Considering the biomechanical adaptations of TTA sprinting athletes using dedicated prostheses, additional compensatory mechanism have been identified (i.e. increased extension moment and increased amount of work done at the residual knee) (Table 4). ${ }^{42}$ Comparing (prosthetic) limb kinematics of amputee sprinters to AB sprinters, TTA sprinters were similar to AB sprinters whereas TFA sprinters showed larger kinematic asymmetry between contralateral limbs during sprinting and showed a gait more typical of walking. ${ }^{41}$ Additionally, comparing a bilateral TTA sprinter to $A B$ sprinters, physiologically they were similar (Table 4), ${ }^{39}$ while clear biomechanical differences were demonstrated. ${ }^{39,40}$ The TTA sprinter demonstrated a shorter swing time (possibly due to the reduced mass of the prostheses compared to a biological limb) and an increased contact time. The ground reaction force seen have been cited as a determinant of increased sprinting speed. ${ }^{46}$ However, the reduced ground reaction force seen for this TTA sprinter was markedly reduced compared to the $\mathrm{AB}$ sprinters, suggesting force impairment ${ }^{39,40,47}$ which may be compensated by the increased contact time to produce a similar propulsive impulse.

\section{Insert Table 4 about here}

\section{Discussion}

The aim of this review was to give an overview of biomechanical research and its relevance for performance in Paralympic sports covering all sports and disabilities which have been published in the literature. Several practical matters regarding technical optimizations, injury prevention and classification were found to help coaches and athletes to improve.

Besides providing understanding in technical optimization and injury prevention, biomechanical research is fundamental for evidence-based classification, where it is important to understand how different impairments limit sports activities. ${ }^{48}$ To be able to classify athletes in such a way that the influence of the athletes' impairment on sport performance is limited, biomechanics have been studied in sitting ${ }^{5,6,17,32}$ and swimming athletes, ${ }^{11}$ while limited data ${ }^{10}$ have been reported on standing athletes. Future research is encouraged to study 
biomechanics in the context of evidence-based classification, to ensure fair and equal competition and optimal performance in Paralympic athletes.

Paralympic summer sports $(n=29,85 \%)$ were studied far more than winter sports $(n=5$, $15 \%)$ in sitting as well as standing athletes. Obviously, the number of summer sports $(n=23)$ performed at the Paralympic Games is higher than the number of winter sports $(n=5)$. However, out of five winter sports, only cross-country sit-skiing and ice-sledge hockey were evaluated using biomechanical analyses. The results on cross-country sit-skiing and ice-sledge hockey provided scientific evidence for setting up optimal training programs, directed to improve performance in elite cross country sitting athletes ${ }^{7}$ and ice-sledge hockey players. ${ }^{21,28}$ Future research is encouraged to investigate biomechanics in alpine skiing, snowboarding, biathlon, and wheelchair curling, to provide coaches and athletes with scientific evidence useful for optimizing performance or to establish evidence-based classification in (new) Paralympic sports. Biomechanical understanding already provides insights in performance enhancement in several summer sports ${ }^{3-6,8-13,17,18,22,24-27,30,32-34}$ and is important for developing training programs aimed at optimizing performance and preventing injuries.

Laboratory testing allows studying movements in a well-structured and controlled way. However, field based testing has the potential to provide a more valid outcome than laboratory testing because athletes are in their natural environment. ${ }^{49}$ It has been stated that specific knowledge relevant for optimal performance is rooted in a direct experience of a meaningful individual-environment process, and that the environment is therefore of influence on the decisions athletes make in competition. ${ }^{50}$ Consequently, the environment as well as the ecological validity of the studies (i.e. are the participants in the studies cited in this review performing sports specific movements or performing as they would in competition?) play an important role in performance and classification respectively. Future research is encouraged to continue to link the well-controlled laboratory outcomes to valid field based outcomes.

Wheeled sports and SCI athletes take a prominent place in the literature. Many biomechanical studies were performed in wheeled sports, mainly because of the complex athlete-device interface, in which changes in both the athlete and the wheelchair affect performance. $^{49}$ Especially after the introduction of the SMART ${ }^{\text {Wheel }}{ }^{44}$ data collection of forces and moments applied to the push-rim of daily wheelchairs became much easier, increasing biomechanical data collection in wheelchair research. In addition, SCI is a devastating paralysis resulting in many secondary impairments, that primarily affects young adults. Despite a relatively low incidence of SCI (9.2-83 per million people per year), and an estimated prevalence of 223-755 per million inhabitants. ${ }^{51}$ this can explain the fact that SCI, and therefore wheelchair athletes and wheeled sports, is a well-researched area. However, there is a paucity of research in to other impairments and non-wheeled sports. This suggests that future biomechanics research will have a lot to offer in developing gains in performance and injury prevention of Paralympic athletes.

Consistent with a previous literature review on the contribution of biomechanical research in performance improvement in a selection of summer sports, ${ }^{1}$ we found that wheelchair and amputee athletes were studied most frequently, whereas little biomechanical research has been conducted on visually-impaired athletes or athletes with CP. Yet, as it has been shown that injuries in visually-impaired athletes are mostly caused by falls, ${ }^{52}$ usually a result of instability, it seems that biomechanical research can contribute to gain understanding in the effect of visual impairment on balance, and subsequently contribute to performance enhancement and injury prevention in visually-impaired athletes. Future research is encouraged to investigate biomechanics in a wide range Paralympic sports and extend the biomechanical knowledge in all fields of sports science.

Besides biomechanical measures, several studies have included physiological measures, ${ }^{16,20,21,28,39}$ as the combination of biomechanical and physiological parameters could 
teach us even more about performance and performance enhancement, allowing the assessment of capability of the human body as well as the resulting movement. For example, comparisons of biomechanical and physiological measures in sprinting athletes showed that running on dedicated, lower-limb sprinting prostheses was physiologically similar but mechanically different from able-bodied running. ${ }^{39}$ Also in cycling, biomechanical differences were found between able-bodied athletes and athletes with $\mathrm{CP}$, while there were physiological similarities. ${ }^{20}$ Lastly, correlations between physiological and kinematic parameters were found in ice sledge hockey, ${ }^{21,28}$ indicating that physiological training adaptations might also affect optimal use of biomechanical principles and technical ability. Future studies are advised to focus on physiological as well as biomechanical principles to be able to better understand performance and performance enhancement.

\section{Practical Applications and Conclusions}

Biomechanical research has contributed greatly to increased understanding of performance enhancement and injury prevention in Paralympic athletes. Also, biomechanical research is fundamental for evidence-based classification, where it is important to understand how different impairments are limiting sports activity. Research has focused mainly on athletics, wheeled sports, (hand)cycling, swimming, sit-skiing and ice sledge hockey, largely in SCI and amputee athletes. No biomechanical research was found on archery, boccia, canoe, equestrian, football, goalball, judo, power lifting, rowing, sailing, shooting, sitting volleyball, table tennis, triathlon, alpine skiing and snowboarding, biathlon and wheelchair curling. Besides continuing to deepen knowledge on athletics, wheeled sports, (hand)cycling, swimming sit-skiing and ice sledge hockey, future biomechanical research is encouraged to investigate a wider range of Paralympic sports, to enhance performance, prevent injuries, and relate research in elite athletes to daily rehabilitation practice. Future studies should include physiological and biomechanical analysis to better understand performance and performance enhancement. 


\section{References}

1. Keogh JW. Paralympic sport: an emerging area for research and consultancy in sports biomechanics. Sports Biomech. 2011;10:234-53.

2. Arellano CJ, McDermott WJ, Kram R et al. Effect of Running Speed and Leg Prostheses on Mediolateral Foot Placement and Its Variability. PloS one. 2015;10:1.

3. Boninger ML, Cooper RA, Robertson RN et al. Wrist biomechanics during two speeds of wheelchair propulsion: an analysis using a local coordinate system. Arch Phys Med Rehabil. 1997;78:364-72.

4. Burkett B, Smeathers J, Barker T. Walking and running inter-limb asymmetry for Paralympic trans-femoral amputees, a biomechanical analysis. Prosthet Orthot Int. 2003;27:36-47.

5. Frossard LA, O'Riordan A, Smeathers J. Performance of elite seated discus throwers in F30s classes: part I: does whole body positioning matter? Prosthet Orthot Int. 2013;37:183-91.

6. Frossard LA, O'Riordan A, Smeathers J. Performance of elite seated discus throwers in F30s classes: part II: does feet positioning matter? Prosthet Orthot Int. 2013;37:192-202.

7. Gastaldi L, Pastorelli S, Frassinelli S. A biomechanical approach to Paralympic crosscountry sit-ski racing. Clin J Sport Med. 2012;22:58-64.

8. Nolan L, Patritti BL, Simpson KJ. A biomechanical analysis of the long-jump technique of elite female amputee athletes. Med Sci Sports Exerc. 2006;38:1829-35.

9. Nolan L, Patritti BL. The take-off phase in TTA amputee high jump. Prosthet Orthot Int. 2008;32:160-71.

10. Nolan L, Patritti BL, Stana L et al. Is increased residual shank length a competitive advantage for elite transtibial amputee long jumpers? Adapt Phys Activ Q. 2011;28:26776.

11. Oh, YT, Burkett B, Osborough C et al. London 2012 Paralympic swimming: passive drag and the classification system. Br J Sports Med. 2013;47:838-43.

12. Taboga P, Kram R, Grabowski AM. Maximum-speed curve-running biomechanics of sprinters with and without unilateral leg amputations. J. Exp. Biol. 2016;219:851-58

13. Burkett B, Smeathers J, Barker T. Optimising the trans-femoral prosthetic alignment for running, by lowering the knee joint. Prosthet Orthot Int. 2001;25:210-9.

14. Dingley AA, Pyne DB, Youngson J et al. Effectiveness of a dry-land resistance training program on strength, power and swimming performance in Paralympic swimmers. $J$ Strength Cond Res. 2014;29:619-26.

15. Dingley A, Pyne DB, Burkett B. Phases of the Swim-start in Paralympic Swimmers are Influenced by Severity and Type of Disability. J Appl Biomech. 2014;30;643-48.

16. Dingley AA, Pyne DB, Burkett B. Relationships Between Propulsion and Anthropometry in Paralympic Swimmers. IJSPP. 2015;doi: 10.1123/ijspp.2014-0186

17. Frossard L. Performance dispersion for evidence-based classification of stationary throwers. Prosthet Orthot Int. 2012;36:348-55.

18. Fulton SK, Pyne DB, Burkett B. Quantifying freestyle kick-count and kick-rate patterns in Paralympic swimming. J Sports Sci. 2009;27:1455-61.

19. Langelier E, Martel S, Millot A et al. A sit-ski design aimed at controlling centre of mass and inertia. $J$ Sports Sci. 2013;31:1064-73.

20. Runciman P, Derman W, Ferreira S et al. A descriptive comparison of sprint cycling performance and neuromuscular characteristics in able-bodied athletes and paralympic athletes with cerebral palsy. Am J Phys Med Rehab. 2015;94:28-37.

21. Skovereng K, Ettema G, Welde B et al. On the Relationship Between Upper-Body Strength, Power, and Sprint Performance in Ice Sledge Hockey. J Strength Cond Res. 2013;27:3461-6. 
22. Wang YT, Chen S, Limroongreungrat $\mathrm{W}$ et al. Contributions of selected fundamental factors to wheelchair basketball performance. Med Sci Sports Exerc. 2005;37:130-7.

23. Bernardi M, Janssen T, Bortolan L et al. Kinematics of cross-country sit skiing during a Paralympic race. J Electromyogr Kinesiol. 2013;23:94-101.

24. Boninger ML, Cooper RA, Robertson RN et al. Three-dimensional pushrim forces during two speeds of wheelchair propulsion. Am J Phys Med Rehabil. 1997;76:420-6.

25. Boninger ML, Cooper RA, Shimada SD et al. Shoulder and elbow motion during two speeds of wheelchair propulsion: a description using a local coordinate system. Spinal Cord. 1998;36:418-26.

26. Fulton SK, Pyne DB, Burkett B. Validity and reliability of kick count and rate in freestyle using inertial sensor technology. J Sports Sci. 2009;27:1051-8.

27. Nolan L, Patritti BL, Simpson KJ. Effect of take-off from prosthetic versus intact limb on transtibial amputee long jump technique. Prosthet Orthot Int. 2012;36:297-305.

28. Sandbakk $\varnothing$, Hansen $M$, Ettema $G$ et al. The effects of heavy upper-body strength training on ice sledge hockey sprint abilities in world class players. Hum Movement Sci. 2014;38:251-61.

29. Silva A, Zanca G, Winckler $\mathrm{C}$ et al. Isokinetic Assessment and Musculoskeletal Complaints in Paralympic Athletes. Am $J$ Phys Med Rehab. 2015;doi:10.1097/PHM.0000000000000244

30. Habora H, Potthast W, Sano Y et al. Does amputation side influence sprint performances in athletes using running-specific prostheses? SpringerPlus. 2015;4:670

31. Dyer B., Noroozi S., Sewell P. Sprinting with an amputation: Some race-based lower-limb step observations. Prosthet Orthot Int. 2014;doi:10.1177/0309364614532863

32. Frossard L, Smeathers J, O'Riordan A, Goodman S. Shot trajectory parameters in gold medal stationary shot-putters during world-class competition. Adapt Phys Activ $Q$. 2007;24:317-31.

33. Fulton SK, Pyne D, Burkett B. Optimizing kick rate and amplitude for Paralympic swimmers via net force measures. J Sports Sci. 2011;29:381-7.

34. Groen WG, van der Woude LH, De Koning JJ. A power balance model for handcycling. Disabil Rehabil. 2010;32:2165-71.

35. McGowan CP, Grabowski AM., McDermott WJ et al. Leg stiffness of sprinters using running-specific prostheses. $J$ R Soc Interface. 2012; doi:10.1098/rsif.2011.0877

36. Pradon D, Mazure-Bonnefoy A, Rabita G et al. The biomechanical effect of arm mass on long jump performance: A case-study of a Paralympic upper limb amputee. Prosthet Orthot Int. 2014;38:248-52.

37. Baur H, Stapelfeldt B, Hirschmuller A et al. Functional benefits by sport specific orthoses in a female Paralympic cyclist: A case report. Foot Ankle Int.2008;29:746-51.

38. Costa GB, Rubio MP, Belloch SL et al. Case-study: Effect of handrim diameter on performance in a Paralympic wheelchair athlete. Adapt Phys Act Q. 2009;26:352-63.

39. Weyand PG, Bundle MW, McGowan CP et al. The fastest runner on artificial legs: different limbs, similar function? J Appl Physiol. 2009;107:903-11.

40. Brüggeman GP, Arampatzis A, Emrich F et al. Biomechanics of double transtibial amputee sprinting using dedicated sprinting prostheses. Sports Technology 2008;1:220-7.

41. Buckley JG. Sprint kinematics of athletes with lower-limb amputations. Ach Phys Med Rehabil. 1999;80:501-8.

42. Buckley JG. Biomechanical adaptations of transtibial amputee sprinting in athletes using dedicated prostheses. Clin Biomech. 2000;15:352-8.

43. Bernardi M, Carucci S, Faiola F et al. Physical fitness evaluation of Paralympic winter sports sitting athletes. Clin J Sport Med. 2012;22:26-30. 
44. Cooper RA. SMARTWheel: From concept to clinical practice. Prosthet Orthot Int. 2009;33:198-209.

45. Taylor MJ and Beneke R. Spring mass characteristics of the fastest men on Earth. Int $J$ Sports Med. 2012;33:667-70.

46. Weyand PG, Sternlight DB, Bellizzi MJ et al. Faster top running speeds are achieved with greater ground forces not more rapid leg movements. J Appl Physiol. 2000; 86:1991-99.

47. Grabowski AM, McGowan CP, McDermott WJ et al. Running-specific prostheses limit ground-force during sprinting. Biol Lett. 2010;6:201-4.

48. Tweedy SM, Vanlandewijck YC. International Paralympic Committee Position Standbackground and scientific rationale for classification in Paralympic sport. Br J Sports Med. 2010;43(8):259-69.

49. Goosey-Tolfrey VL, Leicht CA. Field-based physiological testing of wheelchair athletes. Sports Med. 2013;43:77-91.

50. Smits BL, Pepping GJ, Hettinga FJ. Pacing and decision making in sport and exercise: the roles of perception and action in the regulation of exercise intensity. Sports Med 2014;44:763-75.

51. Wyndaele $M$ and Wyndaele JJ. Incidence, prevalence and epidemiology of spinal cord injury: what learns a worldwide literature survey? Spinal cord. 2006;44:523-9.

52. Webborn N, Willick S, Emery CA. The injury experience at the 2010 Winter Paralympic games. Clin J Sport Med. 2012;22:3-9. 
Table 1 Biomechanical studies of seated Paralympic summer and winter sports. The topics technical optimization $(\mathrm{T}=$ technical optimization), injury prevention ( $\mathrm{I}=$ injury prevention $)$ and evidence-based classification $(\mathrm{E}=$ Evidence classification) are indicated.

\begin{tabular}{|c|c|c|c|c|c|}
\hline Study & $\mathrm{n}$ participants & Sport & Impairment & Test & Outcome \\
\hline \multicolumn{6}{|l|}{ Summer } \\
\hline $\begin{array}{l}\text { Boninger et } \\
\text { al. } 3,24,25[\mathrm{~T}, \mathrm{I}]\end{array}$ & 6 & $\begin{array}{l}\text { Table Tennis; } \\
\text { weight training, } \\
\text { Swimming, Target } \\
\text { Shooting, W/chair } \\
\text { Racing }\end{array}$ & $\begin{array}{l}\text { SCI, Spina } \\
\text { Bifida }\end{array}$ & $\begin{array}{l}\text { WC propelling on a } \\
\text { dynamometer at } 1.3 \mathrm{~m} / \mathrm{s} \\
\text { and } 2.2 \mathrm{~m} / \mathrm{s} \text { to asses } 3 \mathrm{D} \\
\text { pushrim forces, wrist, } \\
\text { shoulder, and elbow } \\
\text { biomechanics }\end{array}$ & $\begin{array}{l}\text { Pushrim forces: Peak force tangential to } \\
\text { pushrim, peak moments radial to hub, maximum } \\
\text { rate of rise of tangential force and moment } \\
\text { about hub were stable parameters but differed } \\
\text { between the two speeds. }\end{array}$ \\
\hline & & & & & $\begin{array}{l}\text { Wrist biomechanics: Maximum radial } \\
\text { deviation, peak flexion moment, and peak } \\
\text { extension moment differed between the two } \\
\text { speeds }\end{array}$ \\
\hline & & & & & $\begin{array}{l}\text { Shoulder and elbow biomechanics: Maximum } \\
\text { radial deviation, peak flexion moment, peak } \\
\text { extension moment differed between the two } \\
\text { speeds }\end{array}$ \\
\hline Frossard $^{17[T, E]}$ & 114 & $\begin{array}{l}\text { Stationary Shot } \\
\text { Putting }\end{array}$ & $\begin{array}{l}\text { Multiple. F30s } \\
\text { and F50s class }\end{array}$ & $\begin{array}{l}\text { Analysis of } 479 \text { attempts } \\
\text { by male and female during } \\
\text { the } 2008 \text { PG }\end{array}$ & $\begin{array}{l}\text { There was a linear relationship between best } \\
\text { performance and classification. }\end{array}$ \\
\hline $\begin{array}{l}\text { Frossard et } \\
\text { al. }^{32[T, E]}\end{array}$ & $\begin{array}{l}\text { Best attempt of the } \\
\text { best men }(n=4) \text { and } \\
\text { women }(n=3) \text { at } \\
\text { each event. }\end{array}$ & $\begin{array}{l}\text { Stationary Shot } \\
\text { Putting }\end{array}$ & na & $\begin{array}{l}\text { Video-recording - } 2000 \\
\text { PG and } 2002 \mathrm{WCh}\end{array}$ & $\begin{array}{l}\text { Release velocity of shot and angle of shot's } \\
\text { trajectory } \uparrow \text { with performance and classification } \\
\text { for males and females. }\end{array}$ \\
\hline $\begin{array}{l}\text { Frossard et } \\
\text { al. } 5[\mathrm{~T}, \mathrm{E}]\end{array}$ & 12 & $\begin{array}{l}\text { Seated Discus } \\
\text { Throwing }\end{array}$ & $\begin{array}{l}\text { F30 class: } \\
\text { limited control } \\
\text { of legs, trunk, } \\
\text { arms and } \\
\text { hands }\end{array}$ & $\begin{array}{l}\text { Video-recording of WBP - } \\
2002 \mathrm{WCh} \text {. }\end{array}$ & $\begin{array}{l}\text { Multiple combinations of throwing postures - } \\
\text { including 3-6 points of contact, throwing from a } \\
\text { standing or seated position, using a straddle, } \\
\text { stool or chair. }\end{array}$ \\
\hline
\end{tabular}


Table 1 continued

\begin{tabular}{|c|c|c|c|c|c|}
\hline Study & $\mathrm{n}$ participants & Sport & Impairment & Test & Outcome \\
\hline $\begin{array}{l}\text { Groen et } \\
\text { al. }^{34[T]}\end{array}$ & 4 & Hand Cycling & $\begin{array}{l}\text { SCI, TFA, } \\
\text { PTD }\end{array}$ & $\begin{array}{l}250 \mathrm{~m} \text { indoor track } \\
\text { cycling }\end{array}$ & $\begin{array}{l}\mathrm{PO}=0.20 \mathrm{v} 3+2.90 \mathrm{v}(\mathrm{R} 2=0.95) \text { Mean } \mathrm{GE}= \\
17.9 \% \pm 1.6 \% . \text { Performance can be modeled } \\
\text { with a power balance model. }\end{array}$ \\
\hline $\begin{array}{l}\text { Wang et } \\
\text { al. }^{22[T, I]}\end{array}$ & 37 & $\begin{array}{l}\text { Wheelchair } \\
\text { Basketball }\end{array}$ & Multiple & $\mathrm{RT}$, arm goniometry & $\begin{array}{l}\uparrow \text { Elbow and wrist extension ROM }=\operatorname{sig} \uparrow \\
\text { average points. } \\
\uparrow \text { sitting height, shoulder internal rotation and } \\
\text { elbow flexion = sig } \uparrow \text { average rebounds. } \\
\uparrow \text { arm length sig } \uparrow \text { average assists. } \\
\text { Quick vision RT sig } \uparrow \text { increased number of } \\
\text { blocks. } \\
\uparrow \text { Wrist Flex/Ext ROM and strength sig } \uparrow \\
\text { increased overall performance. }\end{array}$ \\
\hline Winter & & & & & \\
\hline $\begin{array}{l}\text { Bernardi et } \\
\text { al. }^{23[T]}\end{array}$ & 10 & $\begin{array}{l}\text { Cross-Country Sit- } \\
\text { Skiing }\end{array}$ & $n a$ & $\begin{array}{l}\text { Video-recordings during } \\
15 \mathrm{~km}-2006 \mathrm{PG}\end{array}$ & $\begin{array}{l}\text { Speed sig } \uparrow \text { in G1 than in G2 in flat and uphill } \\
\text { track. G1 maintained the high-speed better than } \\
\text { G2 over the entire race. G1 showed } \uparrow \text { physical } \\
\text { fitness than G2. }\end{array}$ \\
\hline
\end{tabular}


Table 1 continued

\begin{tabular}{|c|c|c|c|c|c|}
\hline Study & $\mathrm{n}$ participants & sport & impairment & test & outcome \\
\hline
\end{tabular}


Table 2 Biomechanical studies of standing Paralympic summer sports. The topics technical optimization $(\mathrm{T}=$ technical optimization $)$, injury prevention $(\mathrm{I}=$ injury prevention) and evidence-based classification $(\mathrm{E}=$ Evidence classification) are indicated

\begin{tabular}{|c|c|c|c|c|c|}
\hline Study & $\begin{array}{l}\mathrm{n} \\
\text { participants }\end{array}$ & Sport & Impairment & Test & Outcome \\
\hline $\begin{array}{l}\text { Arellano } \\
\text { et al. }{ }^{2[\mathrm{~T}]}\end{array}$ & $\begin{array}{l}12 \mathrm{AB}, 7 \\
\mathrm{TTA}\end{array}$ & $\begin{array}{l}\text { Sprinting } \\
(\max 7.0 \\
-9.7 \mathrm{~m} / \mathrm{s})\end{array}$ & $\begin{array}{l}\text { UL and BL } \\
\text { TTA, AB }\end{array}$ & $\begin{array}{l}\text { Midline of the body and CoP in the } \\
\text { ML direction during running up to } \\
\text { maximum speeds on a force } \\
\text { measuring treadmill }\end{array}$ & $\begin{array}{l}\text { ML FPV } \uparrow \text { and was symmetrical across speed in AB and } \uparrow \text { and } \\
\text { was asymmetrically across speed in UL TTA. BL TTA showed } \\
\text { the greatest increase in ML FPV with speed. }\end{array}$ \\
\hline $\begin{array}{l}\text { Burkett et } \\
\text { al. }^{4,13 T]}\end{array}$ & 4 & Sprinting & UL TFA & $\begin{array}{l}\text { Video and force plate analysis } \\
\text { during walking and maximal running } \\
\text { speed on modified running } \\
\text { prosthesis }\end{array}$ & $\begin{array}{l}\text { Lowering the prosthetic knee joint center improved inter-limb } \\
\text { symmetry and subsequently running velocity by } \pm 26 \% \text {. Better } \\
\text { inter-limb asymmetry was identified in walking than in sprinting. }\end{array}$ \\
\hline $\begin{array}{l}\text { Dyer et } \\
\text { al. }^{31[T]}\end{array}$ & 7 male & $\begin{array}{l}100 \mathrm{~m} \\
\mathrm{~T} 44 / 43\end{array}$ & $\begin{array}{l}\text { UL and BL } \\
\text { TTA }\end{array}$ & $\begin{array}{l}\text { Video analysis major events from } \\
1996-2012 . \text { Step count and step } \\
\text { limb-to-limb symmetry } \\
\text { characteristics. }\end{array}$ & $\begin{array}{l}\text { A low step count ( }<50 \text { steps) may help athletes to achieve better } \\
\text { results in } 100 \mathrm{~m} \text { sprint. Limb-to-limb imbalances were found. }\end{array}$ \\
\hline $\begin{array}{l}\text { Nolan et } \\
\text { al. }^{8[T]}\end{array}$ & 17 female & $\begin{array}{l}\text { Long } \\
\text { Jump }\end{array}$ & $\begin{array}{l}\text { UL TFA, } \\
\text { TTA }\end{array}$ & $\begin{array}{l}\text { Doppler device and video-recordings } \\
\text { - } 2004 \text { PG }\end{array}$ & $\begin{array}{l}\text { TFA CoM height in the last three steps before TO was } \uparrow \text { than } \\
\text { TTA. From last touch-down to TO, CoM was } \downarrow \text { in TFA than in } \\
\text { TTA. }\end{array}$ \\
\hline $\begin{array}{l}\text { Nolan et } \\
\text { al. }{ }^{9[T]}\end{array}$ & 2 & $\begin{array}{l}\text { High } \\
\text { Jump }\end{array}$ & UL TTA & Video-recordings - 2004 PG & $\begin{array}{l}\downarrow \text { horizontal approach velocity, } \\
\downarrow \text { vertical TO velocity, } \uparrow \text { upright position at TD and } \uparrow \text { hip ROM } \\
\text { TO phase compared to AB. }\end{array}$ \\
\hline $\begin{array}{l}\text { Nolan et } \\
\text { al. }{ }^{10[T, E]}\end{array}$ & 16 & $\begin{array}{l}\text { Long } \\
\text { Jump }\end{array}$ & UL TTA & $\begin{array}{l}\text { Video-recordings - } 1998 \text { and } 2002 \\
\text { WCh and } 2004 \text { PG }\end{array}$ & $\begin{array}{l}\text { Residual shank length was not an important determinant of Long } \\
\text { Jump performance. }\end{array}$ \\
\hline $\begin{array}{l}\text { Nolan et } \\
\text { al. }^{27[T]}\end{array}$ & 10 & $\begin{array}{l}\text { Long } \\
\text { Jump }\end{array}$ & UL TTA & $\begin{array}{l}\text { Doppler device and video-recordings } \\
\text { - } 2004 \text { PG }\end{array}$ & $\begin{array}{l}\text { At TD before TO prosthetic limb showed significantly } \downarrow \text { hip } \\
\text { ROM and } \downarrow \text { knee ROM and maximal knee flexion compared to } \\
\text { intact limb. Prosthetic limb TO showed more horizontal velocity } \\
\text { than intact limb TO. }\end{array}$ \\
\hline
\end{tabular}


Table 2 continued

\begin{tabular}{|c|c|c|c|c|c|}
\hline Study & $\begin{array}{l}\mathrm{n} \\
\text { participants }\end{array}$ & Sport & Impairment & Test & Outcome \\
\hline $\begin{array}{l}\text { Runciman } \\
\text { et al. }{ }^{20[T]}\end{array}$ & $\begin{array}{l}5 \mathrm{CP}, 16 \\
\mathrm{AB}\end{array}$ & $\begin{array}{l}\text { Sprinting; } \\
\text { T38/T39 }\end{array}$ & $\mathrm{CP}$ & $\begin{array}{l}\text { PO and fatigue index (\%) during a } \\
30 \mathrm{sec} \text { Wingate cycle test. Bilateral } \\
\text { leg EMG. }\end{array}$ & $\begin{array}{l}\mathrm{PO} \text { was sig } \uparrow \text { in the } \mathrm{AB} \text { group }(10.5 \pm 0.5 \mathrm{~W} / \mathrm{kg}) \text { than in the } \mathrm{CP} \\
\text { group }(9.8 \pm 0.5 \mathrm{~W} / \mathrm{kg}) \text {. Fatigue index was similar between } \mathrm{AB} \\
(27 \% \pm 0.1 \%) \text { and } \mathrm{CP}(25 \% \pm 0.1 \%) \text { groups. EMG amplitude } \\
\text { and frequency changed similarly in all muscle groups tested, in } \\
\text { the } \mathrm{CP} \text { and } \mathrm{AB} \text { groups. }\end{array}$ \\
\hline $\begin{array}{l}\text { Silva et } \\
\text { al. }^{29[1]}\end{array}$ & $\begin{array}{l}10 \text { male, } 4 \\
\text { female }\end{array}$ & Athletics & $\begin{array}{l}\text { VI, LD, } \\
\text { Athlete } \\
\text { guides }\end{array}$ & $\begin{array}{l}\text { Self-reported musculoskeletal } \\
\text { complaints and muscle strength } \\
\text { assessed } 3 \text { times over a year before } \\
\text { competition }\end{array}$ & $\begin{array}{l}\text { Knee flexor and extensor muscle strength sig } \uparrow \text { in both limbs at } \\
\text { the second and third assessments compared to the first. Muscle } \\
\text { imbalance was associated with knee and thigh complaints. }\end{array}$ \\
\hline $\begin{array}{l}\text { Hobara et } \\
\text { al. }{ }^{30[T]}\end{array}$ & $\begin{array}{l}59 \text { male } \\
\text { and female }\end{array}$ & Sprinting & UL TTA & $\begin{array}{l}\text { Analysis from publicly available } \\
\text { Internet broadcast of Paralympic and } \\
\text { International } 200 \mathrm{~m} \text { races }\end{array}$ & $\begin{array}{l}\text { No significant differences in race times between left and right } \\
\text { side amputees were found. }\end{array}$ \\
\hline
\end{tabular}


Table 3 Biomechanical studies of Paralympic swimming. The topics technical optimization $(\mathrm{T}=$ technical optimization $)$, injury prevention $(\mathrm{I}=$ injury prevention) and evidence-based classification ( $\mathrm{E}=$ Evidence classification) are indicated.

\begin{tabular}{|c|c|c|c|c|}
\hline Study & $\mathrm{n}$ participants & Impairment & Test & Outcome \\
\hline $\begin{array}{l}\text { Dingley } \\
\text { et al. }{ }^{14[T, I]}\end{array}$ & $\begin{array}{l}1 \text { male, } 6 \\
\text { female }\end{array}$ & $\begin{array}{l}\text { ID, VI, CP } \\
(\mathrm{n}=3), \mathrm{LA}, \\
\mathrm{SS}\end{array}$ & $\begin{array}{l}\text { 6-wk strength training program. Outcome } \\
\text { measure - 50-m time trial and timed dive starts }\end{array}$ & $\begin{array}{l}50 \text {-m time trials improved } 1.2 \% \pm 1.5 \% \text {. Mean power } \uparrow 6.1 \% \\
\pm 5.9 \% \text {, acceleration } \uparrow 3.7 \% \pm 3.7 \% \text { during the start, } \\
\text { improved start times to the } 5-\mathrm{m}(5.5 \% \pm 3.2 \%) \text { and } 15-\mathrm{m} \\
(1.8 \% \pm 1.1 \%) \text { marks. }\end{array}$ \\
\hline $\begin{array}{l}\text { Dingley } \\
\text { et al. }{ }^{15[T]}\end{array}$ & $\begin{array}{l}27 \text { male, } 28 \\
\text { female }\end{array}$ & $\begin{array}{l}\text { VI, ID, CP, } \\
\text { LBI, UBI, } \\
\text { stroke, SS }\end{array}$ & $\begin{array}{l}330 \text { Swim starts collected at national training } \\
\text { camps between 2008-2012 }\end{array}$ & $\begin{array}{l}\text { Regardless of disability, free-swim velocity is a priority area } \\
\text { for improving swim-starts. }\end{array}$ \\
\hline $\begin{array}{l}\text { Fulton et } \\
\text { al. }^{26[T]}\end{array}$ & $\begin{array}{l}8 \text { male, } 4 \\
\text { female }\end{array}$ & $\mathrm{CP}, \mathrm{LA}, \mathrm{AA}$ & $\begin{array}{l}\text { Inertial sensors and video-recordings during } \\
\text { maximal-effort } 100 \mathrm{~m} \text { free-style swim and } \\
100 \mathrm{~m} \text { freestyle kicking-only. }\end{array}$ & $\begin{array}{l}\text { Inertial sensors were a valid and reliable estimate to quantify } \\
\text { changes in kick count and rate in freestyle swimming. }\end{array}$ \\
\hline $\begin{array}{l}\text { Fulton et } \\
\text { al. }^{33[T]}\end{array}$ & $\begin{array}{l}9 \text { male, } 3 \\
\text { female }\end{array}$ & $\begin{array}{l}\text { CP, LA, AA, } \\
\text { VI }\end{array}$ & $\begin{array}{l}\text { Kick rate, dynamometer to assess towing } \\
\text { speed, force-platform to assess net force at the } \\
\text { start }\end{array}$ & $\begin{array}{l}\text { When peak speed } \uparrow \text {, active force } \uparrow \text {, while kick rate remained. } \\
\text { Net force } \uparrow \text { when larger kicking, whereas kick rate } \downarrow \text {. }\end{array}$ \\
\hline $\begin{array}{l}\text { Oh et } \\
\text { al. }{ }^{11[\mathrm{E}]}\end{array}$ & $\begin{array}{l}69 \text { male, } 44 \\
\text { female }\end{array}$ & Multiple & $\begin{array}{l}\text { Electro-mechanical towing device and load cell } \\
\text { - passive drag force during } 2012 \mathrm{PG}\end{array}$ & $\begin{array}{l}\text { Passive drag ranged from } 24.9-82.8 \mathrm{~N} \text {. The current } \\
\text { classification system does not always clearly differentiate } \\
\text { between swimming groups. }\end{array}$ \\
\hline
\end{tabular}


Lower Body Impairment; LSD = Low-Severity Disabilities; PG = Paralympic Games; PD = Physical Disability; SS = Short Stature; UBI = Upper Body Impairment; VI = Visually Impaired 
Table 4 Biomechanical case-studies in Paralympic sports and athletes.

\begin{tabular}{|c|c|c|c|c|c|}
\hline Study & Sport & Impairment & Class & Test & Outcome \\
\hline $\begin{array}{l}\text { Brüggeman } \\
\text { et al. } .^{40}\end{array}$ & $\begin{array}{l}\text { Athletics } \\
\text { (sprints) }\end{array}$ & $\begin{array}{l}\text { One BL TTA, } 5 \\
\text { AB. } 400 \mathrm{~m} \\
\text { performance } \\
\text { matched }\end{array}$ & na & $\begin{array}{l}\text { Running kinematics and } \\
\text { kinetics during maximum } \\
\text { speed running. }\end{array}$ & $\begin{array}{l}\text { TTA total body kinetics } \downarrow \text { mechanical work during stance phase } \\
\text { vs. AB. } \downarrow \text { hip and knee joint kinetics and higher ankle joint } \\
\text { power vs. AB. } \downarrow \text { energy loss at the prosthetic ankle vs. AB ankle. }\end{array}$ \\
\hline Buckley $^{41}$ & $\begin{array}{l}\text { Athletics } \\
\text { (sprints) }\end{array}$ & $\begin{array}{l}\text { UL TTA }(n=4) \\
\text { and TFA }(n=1)\end{array}$ & $n a$ & $\begin{array}{l}\text { Video recordings of the } \\
\text { prosthetic and sound limb } \\
\text { during sprints. Sagittal plane } \\
\text { hip, knee and ankle kinematics. }\end{array}$ & $\begin{array}{l}\text { TTA and AB athletes showed a pattern of stance flexion- } \\
\text { extension for both limbs. For the prosthetic limb (TFA) the knee } \\
\text { was fully extended before and during stance) compared to the } \\
\text { sound limb and AB. }\end{array}$ \\
\hline Buckley $^{42}$ & $\begin{array}{l}\text { Athletics } \\
\text { (sprints) }\end{array}$ & 2 UL TTA & $n a$ & $\begin{array}{l}\text { Repeated maximal sprint trials } \\
\text { using Sprint Flex or Cheetah } \\
\text { prosthesis. }\end{array}$ & $\begin{array}{l}\text { Subject } 1: \uparrow \text { hip extensor moment on the prosthetic limb and } \uparrow \\
\text { concentric work using either prosthesis. } \uparrow \text { total work using Sprint } \\
\text { Flex. Subject } 2: \uparrow \text { extension moment at the residual knee and } \uparrow \text { in } \\
\text { total work using either prosthesis. }\end{array}$ \\
\hline $\begin{array}{l}\text { Pradon et } \\
\text { al. } .^{36}\end{array}$ & $\begin{array}{l}\text { Athletics } \\
\text { (Long } \\
\text { Jump) }\end{array}$ & $\begin{array}{l}\text { Below elbow } \\
\text { amputation }\end{array}$ & F46 & $\begin{array}{l}3 \text { long jumps. One with no } \\
\text { mass added, one with } 0.3 \mathrm{~kg} \\
\text { added and one jump with } 0.4 \\
\mathrm{~kg} \text { added to the prosthetic } \\
\text { wrist. }\end{array}$ & $\begin{array}{l}\text { Long jump distance reduced when mass added. No change in } \\
\text { horizontal velocity during run-up. Adding } 0.4 \mathrm{~kg} \text { mass greatly } \\
\text { perturbed long jump take-off parameters. }\end{array}$ \\
\hline
\end{tabular}


Table 4 Continued

\begin{tabular}{|c|c|c|c|c|c|}
\hline Study & Sport & Impairment & Class & Test & Outcome \\
\hline
\end{tabular}




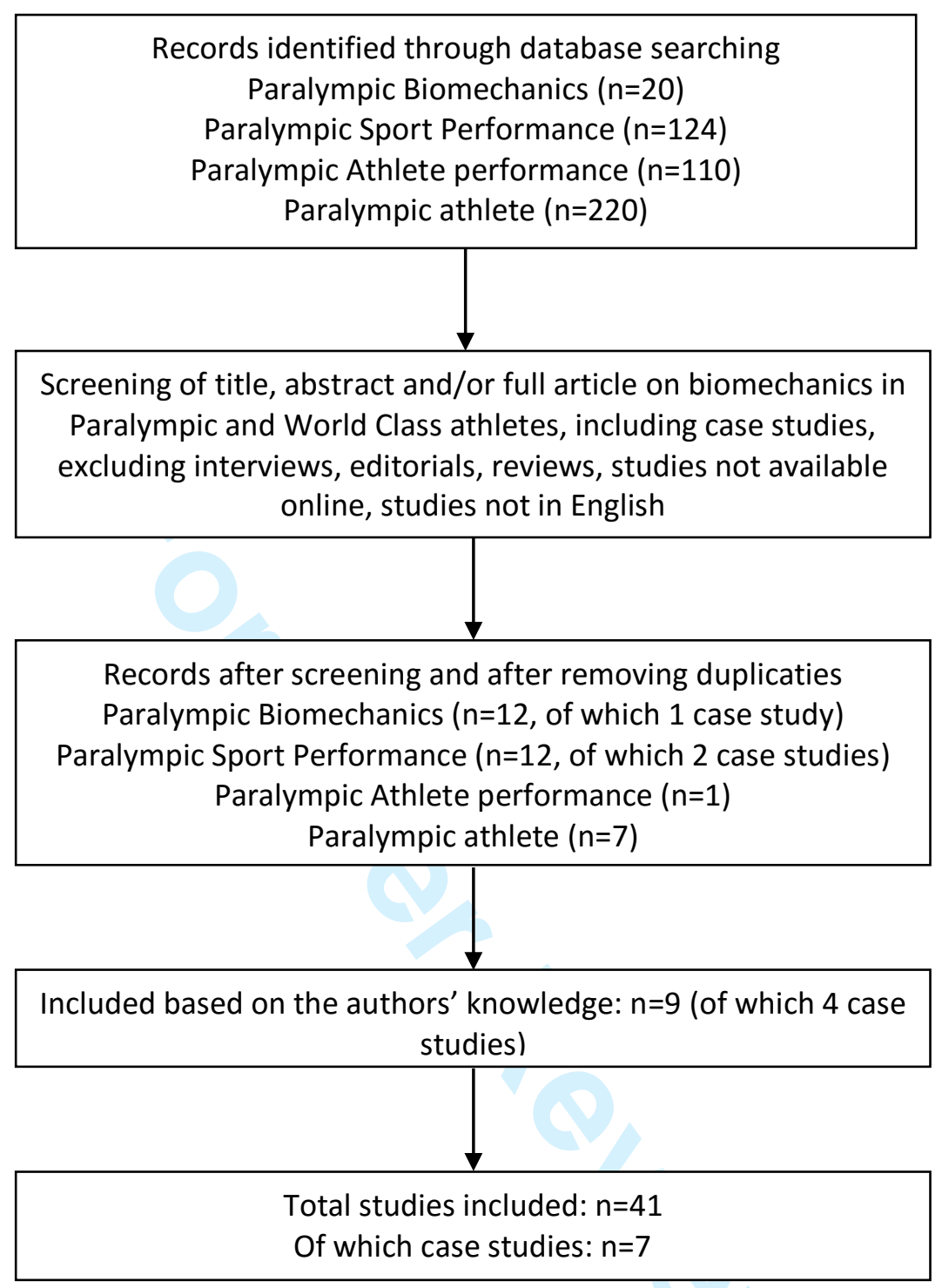

Figure 1 - Flow chart for literature search 